\title{
Using FEM technology for optical surfaces polishing
}

\author{
F. Procháska ${ }^{1}$, J. Polák ${ }^{1}$, D. Tomka ${ }^{1}$ and E. Šubert ${ }^{2}$ \\ ${ }^{1}$ Toptec, Institute of Plasma Physics AS CR, Sobotecká 1660, Turnov 51101, Czech Republic. \\ ${ }^{2}$ Faculty of Nuclear Sciences and Physical Engineering, Czech Technical University in Prague, Břehová 7, 11519 \\ Prague 1, Czech Republic. \\ Correspondence author email: Prochaska@ipp.cas.cz
}

\begin{abstract}
The aim of this article is optical surfaces polishing on the 6-axis computer-controlled (CCM) machine Optotech MCP 250 CNC using FEM technology, which is suitable for aspheric elements polishing. The main attention is dedicated to the choice and to the precise adjustment of major process parameters. The possibility of usage the multi wave interferometer Luphoscan as a data source for the2D surface correction is solved too.
\end{abstract}

\section{Introduction}

In connection with the arrival of interest about aspheric optics used mainly to suppress optical systems spherical aberration [1], considerable progress in a design of aspheric optical element and in a their production is happened. This progress is closely connected also with a significant development of machines and methods for ultra-precision grinding and polishing using a computer controlled CNC (in optics also named CCM) technology. It in combination with suitable measuring device such as aspheric stitching interferometer or multi wave interferometer can product previously unimagined shapes of optical elements.

Aspheric surfaces shape definition is more complicate then sphere surface definition, because must express different shape curvature, which is changed in dependence on radii. For rotation symmetric aspheric elements definition is obviously used formula 1, or alternatively can be used sagittal table (for sag meaning see figure 1) [1]

$$
z=\frac{c r^{2}}{1+\sqrt{1-(1+k) c^{2} r^{2}}}+\sum a_{i} r^{2 i}
$$

Where $\mathrm{z}$ is $\mathrm{z}$ axis value, $\mathrm{c}$ is the base curvature at the vertex, $\mathrm{k}$ is conic constant, $\mathrm{r}$ is the radial coordinate measured perpendicularly from the optical axis, and $a_{i} r^{2 i}$ are higher - order aspheric terms.

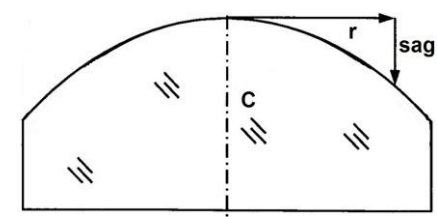

Fig. 1. Sag definition.
Aspheric surface polishing require unlike a traditional flat or spherical surfaces polishing a different attitude, because there is possible to employ traditional technology based on large diameter polishing pads abrasive impact in polishing slurry surrounding only in limited cases. On the contrary there are used technologies with flexible small diameter tools, which are able to smoothly reproduce surface curvature, or technologies based on abrasive impact of focused mass stream (for example Laser fire polishing, Ion beam polishing, Abrasive slurry jet) [2]. Desired shape is reached either by fixed mounted inverse shaped tool and rotate work piece contact or by a point contact tool, when surface shape is generated by controlled tool motion. Into this category fall exactly CCM, which additionally demand periodic repetition of shape measurement step serving for tool path calculation. In category of tools for CCM polishing devices is possible to meet primarily various types of polishing pads glued on rotating planar or spherical carriers operating in the presence of the polishing slurry. In general, these instruments are subject to requirements, such as dimensional stability, constant removal rate in time and possibility of their surface and shape adjustment in dependence of current application. Dependence of the material removal on the tool radii in relation to changing peripheral speed called "Influence function" is typical for these tools. One way how to suppress the "Influence function" is the tool rotary axis tilting in order to shift it out of polishing spot and then apply a precessional tool moving around this axis [3].

Example of a today commercially available CCM device may be six axes polishing machine MCP $250 \mathrm{CNC}$ by Optotech company [4], which offers a wide range of useful polishing technologies (WP, PIM, FEM, AFJ). In connection with aspheric surfaces polishing the membrane technology FEM based on usage of a flexible

This is an Open Access article distributed under the terms of the Creative Commons Attribution License 2.0, which permits unrestricted use, distribution, and reproduction in any medium, provided the original work is properly cited. 
membrane coated by polyurethane foil pressed against polishing surface by pressure air appears effective. Another suitable polishing technology for polishing aspheric elements, especially for the final 3D shape correction is "Active Fluid Jet" based on the rotary action of a small diameter pin with textile pads, which is pressed to the polished surface by the polishing slurry stream. In both cases the cerium oxide or aluminium oxide suspension in water is typically used as a polishing liquid. As already mentioned above, the usage of CCM polishing machine requires an adequate accurate measurement of the surface shape, which serves as a data base for the calculation of the tool path. Some possibilities how can be measured aspheric surfaces exist now. In addition to contact profile measurement instruments can be found mainly interferometric methods such as Verifire Asphere Interferometry or more often Subaperature Stitching Interferometry $[5,6,7]$, based on the sequential interferometric measurement of small space of the surface, from which is then put together the overall surface shape. Another possibility presents multi wave interferometric technique [8], using three or more modulated frequency diode lasers, whose composite beam after passing through the interferometer ("moving" mirror is measured object) is captured by photosensitive diode detector. Thanks to the lasers modulation the detected signal is subsequently separated into individual signals corresponding to the used original wavelengths. Based on this original signals surface topography is then calculated. This principle also uses non-contact multi wave interferometer Luphoscan by Luphos company [9] which allows measuring the relief of rotationally symmetrical polished surfaces (flat, spherical or aspherical) with an accuracy better than $+-50 \mathrm{~nm}$.

\section{Experiments}

\subsection{Polishing}

Polishing experiments were performed on BK7 glass lenses with a diameter of $110 \mathrm{~mm}$ or $70 \mathrm{~mm}$ cemented to steel holders using synthetic resin having a softening point of $60^{\circ} \mathrm{C}$. Desire raw shapes were set on the shape generator MCG $100 \mathrm{CNC}$ by Optotech company using cup instruments with in brass bonded diamond $64 \mu \mathrm{m}$ or for the final grinding $20 \mu \mathrm{m}$ respectively. Polished surface was $100 \mathrm{~mm}$ or. $65 \mathrm{~mm}$ with respect to the risk of polishing tool damage on a surrounding part of lenses. During the experimental work was polished flat, convex sphere $(\mathrm{R}=250 \mathrm{~mm})$ and asphere $(\mathrm{R}=133.2126 \mathrm{~mm}, \mathrm{~A} 4$ $=-2.6934596 \times 10-7$, A6 = 4.0803344 x10-10).

The polishing was carried out by FEM membrane technology on polishing machine MCP $250 \mathrm{CNC}$ by Optotech company, working with polishing slurry Cerox 1670 (Rhodia) at a concentration of about $15 \%$ wt. The individual steps in the order as they were performed during the polishing experiments and the basic geometrical parameters of the polishing tool are shown in Table. 1. Each step was comprised of several polishing cycles. Their duration was related to the process parameters settings and ranged from a few minutes to one hour. So FEM technology was used for the shape and surface polyurethane foil optimization (tool dressing) on a cup diamond bounded grinding tool, then for the footprint, the aim of which was to find such a setup process, when during polishing there is not significant change in the polished surface shape, and to verify these settings correctness for the process stability. FEM was also used for the 2D surface shape corrections focused on removing some rotationally symmetric surface shape variations.

Table 1. Polishing experiments settings.

\begin{tabular}{|l|l|l|}
\hline $\begin{array}{l}\text { Lens diameter } \\
\text { (mm) }\end{array}$ & $\begin{array}{l}\text { Technology and } \\
\text { tool parameters }\end{array}$ & $\begin{array}{l}\text { Polishing } \\
\text { experiment steps }\end{array}$ \\
\hline 110 & $\begin{array}{l}\text { FEM tool D60 } \\
\text { R48 mm }\end{array}$ & $\begin{array}{l}\text { Dressing } \\
\text { Footprint } \\
\text { Process stability } \\
\text { testing }\end{array}$ \\
\hline 70 & FEM tool D32 & $\begin{array}{l}\text { Dressing } \\
\text { Footprint } \\
\text { Flat } \\
\text { Convex sphere } \\
\text { Asphere }\end{array}$ \\
& & $\begin{array}{l}\text { testing } \\
\text { 2D shape } \\
\text { correction }\end{array}$ \\
\hline
\end{tabular}

\subsection{Surface shape measurement}

The surface measurement was performed after each polishing cycle by contactless multi wave interferometer Luphoscan (Luphos company), its measurement parameters are listed in Table 2. Before each measurement the parameters defining a surface shape (radius, aspheric coefficients) and the diameter of the lens, where the measurement was required, were set. Furthermore data resolution according to the specified diameter was optimized, and finally lens height correction measured using the "get height" function was performed. The obtained data were exported to MetroPro format and used as a data base for 2D corrective polishing.

To the structure data analyse, which was designed to verify, that there are no unwanted distortion due to conversion to MetroPro format, MatLab software was used. Scripts for measured surfaces subtraction, such as for surface changing monitoring or for material removing determination, were programmed in MatLab too.

Table 2. Luphoscan - surface shape measurement parameters.

\begin{tabular}{|l|l|}
\hline Parameter & Setting \\
\hline Mode & Polishing surface \\
Velocity & 180 \\
Tilt compensation & Active \\
Shift compensation & Active \\
Display normal & Active \\
2D filtr & Low pass filter, width \\
& $0.86 \mathrm{~mm}$ \\
Cartesian resolution & 501 \\
\hline
\end{tabular}




\section{Results and discussion}

\subsection{Tool dressing and process stability setting}

In the first part of the experimental work basic FEM technology settings were carried out, as recommended the machine manufacturer (see Table 3), including setting of desired surface geometry and dimensions of tools for dressing and polishing.

Table 3. Basic settings for FEM technology.

\begin{tabular}{|c|c|c|c|}
\hline \multicolumn{2}{|c|}{ FEM configuration } & \multicolumn{2}{|c|}{ FEM dressing } \\
\hline Tool radius & 46 resp & Feed rate & 0.2 \\
\hline$(\mathrm{mm})$ & 28 & $(\mathrm{~mm} / \mathrm{min})$. & \\
\hline $\begin{array}{l}\text { Compression } \\
\text { ( bar) }\end{array}$ & 0.5 & Removal (mm) & 0.01 \\
\hline $\begin{array}{l}\text { Tool pressure } \\
\text { (bar) }\end{array}$ & 0.7 & $\begin{array}{l}\text { Sparking out } \\
\text { time }(\mathrm{s})\end{array}$ & 30 \\
\hline $\begin{array}{l}\text { Tool speed } \\
\text { (1/min.) }\end{array}$ & 800 & $\begin{array}{l}\text { Safety } \\
\text { clearance }(\mathrm{mm})\end{array}$ & 0.5 \\
\hline \multirow[t]{2}{*}{$\begin{array}{l}\text { Component } \\
\text { speed }(1 / \mathrm{min} .)\end{array}$} & 775 & $\begin{array}{l}\text { Dressing tool } \\
\text { speed }(1 / \mathrm{min} .)\end{array}$ & 700 \\
\hline & & $\begin{array}{l}\text { Polishing tool } \\
\text { speed ( } 1 / \mathrm{mim} \text {.) }\end{array}$ & -500 \\
\hline
\end{tabular}

When the polishing tool was dressed, a surface of the polishing tool was colored by some marker and to measured length of the polishing tool was added "security" value of $1 \mathrm{~mm}$. Subsequently, dressing cycle was repeatedly performed and after the dressing cycle polishing tool length was reduced about $0.1 \mathrm{~mm}$ until the colored layer was removed.

Correct "Form" and "Depth" parameter adjusting at constant values of other parameters (such as polishing tool rotation speed, the work piece rotation speed, the pressure in the tool, compression, etc.) was necessary before 2D corrective polishing was started, because these parameters are responsible for process shape stability and so for desire 2D correction polishing result. "Form" parameter was set by using Footprint method on 50 or 40 $\mathrm{mm}$ inner diameter of polished lens (see figure 2) or with using "Trial and error" method, when "Form" parameter value was after about twenty minutes long polishing cycles repeatedly readjusted until polishing area shape did not change. Results of these experiments are shown in Table 4.

Table 4. „Form“ and „Depth“ parameter values.

\begin{tabular}{|c|c|c|c|c|}
\hline \multirow{2}{*}{$\begin{array}{l}\text { Polishing } \\
\text { tool }\end{array}$} & \multicolumn{2}{|c|}{ Footprint } & \multicolumn{2}{|c|}{ Trial and error } \\
\hline & $\begin{array}{c}\text { „Form" } \\
(\%)\end{array}$ & $\begin{array}{c}\text {,Depth“" } \\
(\%)\end{array}$ & $\begin{array}{c}\text { „Form“ } \\
(\%)\end{array}$ & $\begin{array}{c}\text { "Depth“" } \\
(\%)\end{array}$ \\
\hline D60 R46 & 109.4 & 256.4 & 90 & $\begin{array}{c}100 \\
\text { (constant) }\end{array}$ \\
\hline D32 R28 & 280.7 & 140.2 & 105 & $\begin{array}{c}100 \\
\text { (constant) }\end{array}$ \\
\hline
\end{tabular}

As experiments showed in the case of "Form" starting value of $100 \%$ and constant "Depth" value of $100 \%$ method "Trial and error" was as time consuming as Footprint method. "Form" parameter resulting values were much different from both methods. It can be probably explained, that Form" parameter and "Depth" parameter were calculated and applied together as two parametric regression analysis result, but in the case of "Trial and error" method only "Form" parameter is changed ("Depth" parameter is constant).

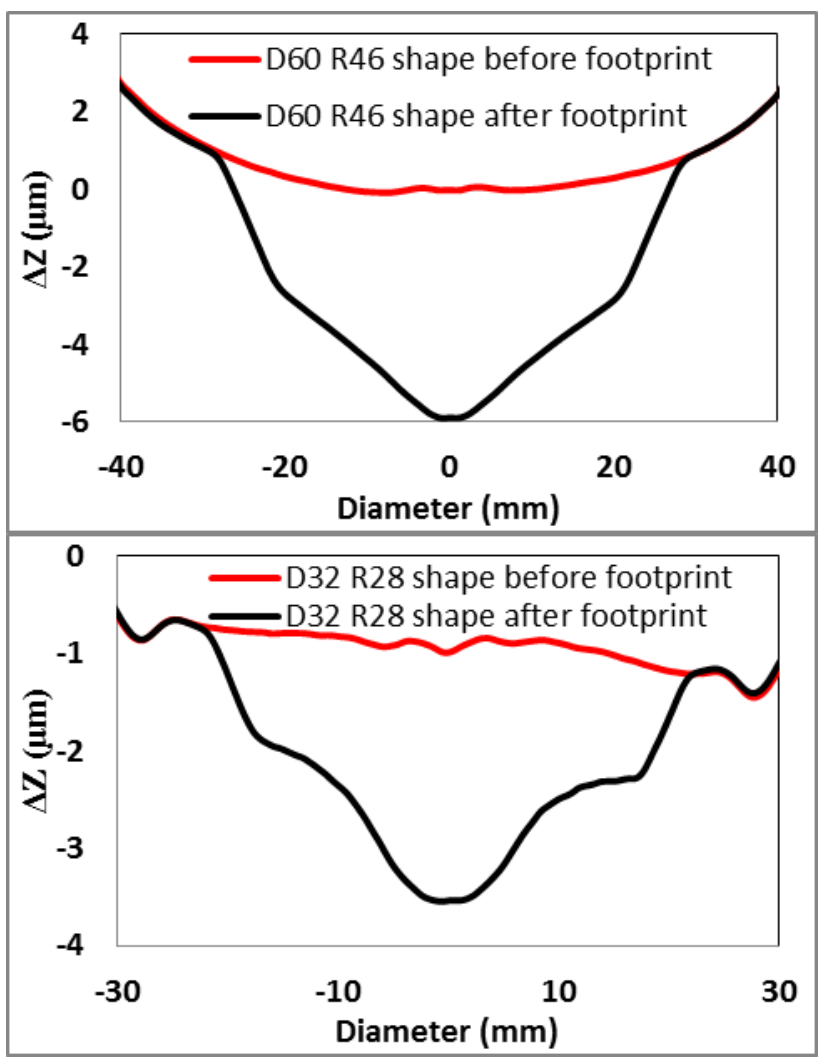

Fig. 2. FEM tool Footprint determination (the tool radius 46 or $28 \mathrm{~mm})$.

\subsection{D correction polishing}

2D correction polishing with tool D32 R28 (settings is shown in Table 5) was performed when a shape of polishing lens at the adjusted "Form" parameter in a two consecutive about 20 minutes long polishing cycles did not significantly change. Results of the 2D corrective polishing of lens (diameter of $70 \mathrm{~mm}$ ), from which the surface gradual improvement is apparent, are shown in Figure 3. Excluding the surround part of lens, where polishing tool material removal function was unstable around tool starting position leading to a concave edge production, the lens shapes has been corrected from an initial value Peak to Valley (PV) $5.5 \mu \mathrm{m}$ to $0.55 \mu \mathrm{m}$. A sharp peaks in the position $\mathrm{r}$ equal about $30 \mathrm{~mm}$, caused by FEM tools instability on the steep edge of the polished surfaces, which were developed with a high number of correction cycles, were limitation for further surface flatness improving. It can be assumed, that with better initial shape after grinding with PV about $1 \mu \mathrm{m}$ can be achieved significantly better flatness and evolution of these peaks will not appear. These facts were 
subsequently confirmed by experiment with 2D correction sphere polishing, whose waveform is shown in Figure 4. The resulting PV value after 3 cycles of 2D correction ranged around $0.15 \mu \mathrm{m}$.

Table 5. Basic 2D correction polishing settings.

\begin{tabular}{|lc|lc|}
\hline \multicolumn{4}{|c|}{ 2D correction polishing } \\
\hline Direction & $\begin{array}{c}\text { edge to } \\
\text { edge } \\
\text { Start position }\end{array}$ & $\begin{array}{l}\text { Point distance } \\
(\mathrm{mm})\end{array}$ & 0,1 \\
Repeat count & 1 & $\begin{array}{l}\text { Max feed } \\
(\mathrm{mm} / \mathrm{min})\end{array}$ & 10000 \\
$\begin{array}{l}\text { Feed function } \\
(\mathrm{mm} / \mathrm{min})\end{array}$ & 2 resp.1.5 \\
\hline
\end{tabular}

When asphere polishing experiments were started, a form of setting the coefficients defining aspherical lens shape was initially necessary to solve. Because the polishing machine works with the opposite orientation of the $\mathrm{z}$ axis than Luphoscan, and witch is commonly used in optical elements drawings, aspherical shape defining equitation was analyzed in the software MatLab. It was founded that the original optical element shape is preserved, when the signs of all entered coefficients were changed. Subsequently, it was decided to verify the process stability using the "Form" and "Depth" parameter values obtained by the Footprint method and it was successfully done. Due to an initial aspherical shape deviation, when PV reaching about $65 \mu \mathrm{m}$, and due to an inability to correct the shape by the grinding, further $2 \mathrm{D}$ corrective polishing was not performed.

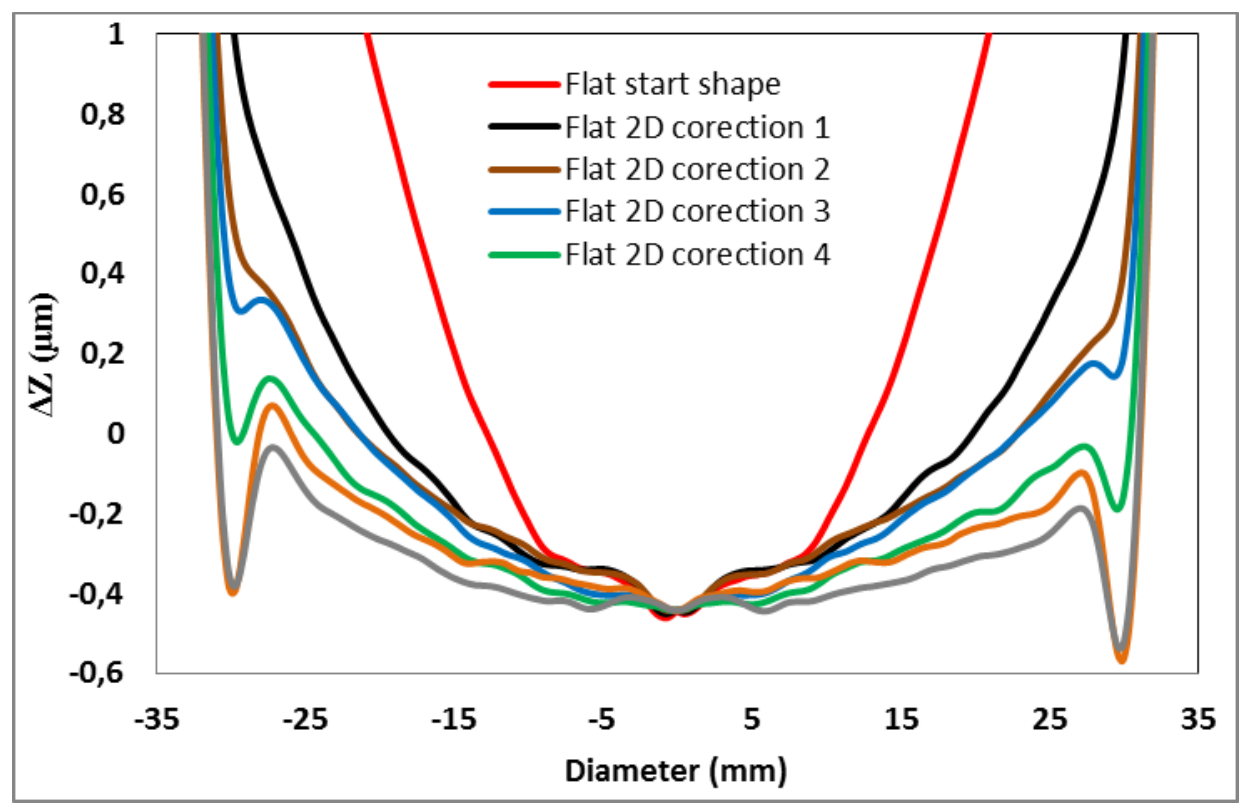

Fig. 3. FEM 2D flat corrective polishing, lens $70 \mathrm{~mm}$, tool D32 R28.

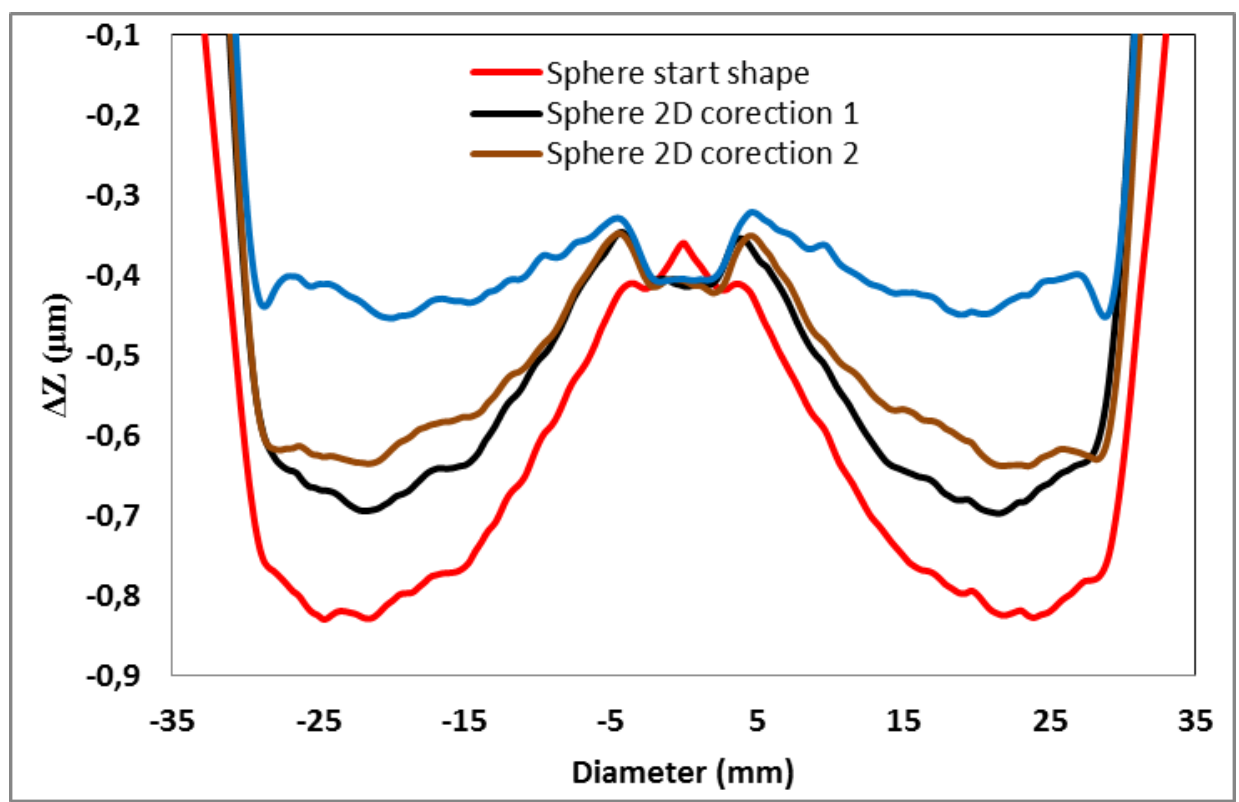

Fig. 4. FEM 2D sphere corrective polishing, lens $70 \mathrm{~mm}$, tool D32 R 


\section{Conclusions}

As accurate "Form" parameter adjustment as possible is very important for proper FEM polishing technology functioning, because this parameter has essential importance for polishing surface shape stability during the polishing process. Footprint method and "Trial and error" method was approximately the same effective in term of time. Although both methods give substantially different values of output parameters, but using the resulting process setup leaded to stable polishing process in both cases.

With the correct polishing machine setting (especially the "Form" and "Depth" parameter) is possible to achieve the precise surface with PV of about $0.2 \mu \mathrm{m}$ only in a several $2 \mathrm{D}$ correction cycles in the case of sufficiently accurate surface generating by grinding with PV value of about $1 \mu \mathrm{m}$. With the growing number of applied 2D correction cycles surface shape damage caused by sharp peaks and a shift development can occur mainly in periphery part of polished element.

The multi wave interferometric measuring device (Luphoscan) usage proved suitable, when adequate attention to the required coefficients convention was given and when were applied odd values of Cartesian resolution for data conversion to MetroPro format.

\section{Acknowledgements}

This work was supported by the European Regional Development Fund and the Ministry of Education, Youth and Sports of the Czech Republic in the Project No. CZ.1.05/2.1.00/03.0079: Research Center for Special Optics and Optoelectronic Systems (TOPTEC).

\section{References}

1. R. E. Fischer, B. T Galeb, P. R. Yoden, Optical system design - secound edition, MC Graw hill companies, 115 - 119, (2008).

2. O. Fahnle, $\mathrm{H}$ van Brug, Conference on optical manufacturing and testing III, Denver Colorado, 170-180, (1999).

3. D. D. Walker, D. Brooks, A. King, R. Freeman, Optic Express, 11 - 8, 958 - 964, (2003).

4. http://www.optotech.de/uk/precision/aspheres/polish ing/ppm-250-cnc/ (draw 21. 9. 2012)

5. Lédl V., Psota P., Václavík J., Rail Z., Jemná mechanika a optika 56-9, 233-236, (2011).

6. Sales Department - Optimax Systems, Inc Optimax Systems, (2008).

7. S. O’Donohue, P. Murphy, J. Fleig, G. Devries, Rochester NY USA: QED Technology.

8. K. Meiners-Hagen R. Schodel, F. Pollinger, A. Abou-Zeid, Measurement science Review, 9-3-1, $16-26,(2009)$.

9. http://www.luphos.de/produkte_LuphoScan_en.html (drawn 21. 9. 2012). 